Article

\title{
Hydrochloric Acid Modification and Lead Removal Studies on Naturally Occurring Zeolites from Nevada, New Mexico, and Arizona.
}

\author{
Garven M. Huntley, ${ }^{a}$ Rudy L. Luck, ${ }^{a *}$ Michael E. Mullins, ${ }^{b}$ and Nick K. Newberrya
}

aDepartment of Chemistry and bepartment of Chemical Engineering, Michigan Technological University, 1400 Townsend Drive, Houghton, MI 49931, USA.

E-mail: rluck@mtu.edu, 9064877137 (W), 9064872061 (F).

\begin{abstract}
Four naturally occurring zeolites AZLB-Ca and AZLB-Na (Bowie, Arizona), NM-Ca (Winston, New Mexico), and NV-Na (Ash Meadows, Nevada) were studied to evaluate structural modifications after treatment with $\mathrm{HCl}$ acid. AZLB-Ca and AZLB-Na are chabazite-like species and become amorphous when boiled in concentrated $\mathrm{HCl}$ acid as confirmed by powder X-ray diffraction. In contrast, NM-Ca and NV-Na which are clinoptilolite-like species withstood boiling in concentrated $\mathrm{HCl}$ acid. This treatment removes calcium, magnesium, sodium, potassium, aluminum, and iron atoms or ions from the framework while leaving the silicon framework intact as confirmed via X-ray fluorescence and diffraction. SEM images on calcined and $\mathrm{HCl}$ treated $\mathrm{NV}-\mathrm{Na}$ were obtained. BET surface area analysis confirmed an increase in surface area for the two zeolites after treatment, NM-Ca (20.0(1) to $111(4) \mathrm{m}^{2} / \mathrm{g}$ ) and NV-Na (19.0(4) to $158(7) \mathrm{m}^{2} / \mathrm{g}$ ). ${ }^{29} \mathrm{Si}$ and ${ }^{27} \mathrm{Al}$ MAS NMR were performed on the natural and treated NV-Na zeolite and the data for the natural NV-Na zeolite suggested a Si:Al ratio of 4.33 similar to that determined by X-Ray fluorescence of 4.55. Removal of lead ions from solution decreased from the native (NM-Ca, $0.27(14), \mathrm{NV}-\mathrm{Na}$, $1.50(17) \mathrm{meq} / \mathrm{g}$ ) compared to the modified zeolites (30 min HCl treated NM-Ca 0.06(9) and NV-Na, $0.41(23) \mathrm{meq} / \mathrm{g}$ ) and also decreased upon $\mathrm{K}^{+}$ion pretreatment in the $\mathrm{HCl}$ modified zeolites.
\end{abstract}

Keywords: Clinoptilolites, Acid modification, heavy metals, toxic substances, purification, lead removal.

\section{Introduction}

Natural zeolites, which are composed of hydrated aluminosilicates containing group I and II metals, [1] are an abundant resource [2] with desirable chemical properties for many different applications such as catalysis and ion exchange [3]. Zeolites have a crystalline structure with small voids commonly called pores that act as a site for the zeolite to capture or stabilize different cations or molecules. They have been utilized to remove salinity/sodicity [4], copper [5], $\mathrm{Cr}^{6+}[6], \mathrm{Mn}^{2+}$ [7], heavy metals [8], ammonia [9], phosphorus [10], purify urine [11], zinc [12] from wastewater and also anions such as $\mathrm{Cl}^{-}$and $\mathrm{CO}_{3}{ }^{2-}$ [13]. Zeolites contain cations to stabilize the negative charge in their structure with $\mathrm{Na}^{+}$, $\mathrm{K}^{+}, \mathrm{Ca}^{2+}$, and $\mathrm{Mg}^{2+}$ being the four most common with others possible [14]. While it is possible to synthesize a single phase of clinoptilolite, [15] as much as $4.75 \mathrm{mg} \mathrm{Fe} / \mathrm{g}$ of Mexican natural zeolite consisting of clinoptilolite, mordenite, and feldspar phases was reported [16].

During the ion exchange process, zeolites absorb toxic metal ions dissolved in solutions into their pores while releasing the other cations present in the structure into the solutions. Thus, water contaminated with $\mathrm{Pb}^{2+}$ ions, which are toxic to humans, could be made safe by stirring with a zeolite to remove the $\mathrm{Pb}^{2+}$ ions from the solution. The $\mathrm{Pb}^{2+}$ 
ions would be contained inside the zeolite and could be easily filtered off and the $\mathrm{Na}^{+}$ion that was previously in the zeolite would now be dissolved in the water rendering it safer for human consumption [17].

We had recently obtained samples of four naturally occurring zeolites which were of the chabazite and clinoptilolite (based on $\mathrm{Si}: \mathrm{Al} \geq 4.0$ [18]) varieties. The chabazite form has been explored for its unusual composition [19] and chemical upgrading, [20], and the clinoptilolite zeolite has been studied for various membrane applications [21-23]. Additionally, both chabazite and clinoptilolite were subjected to treatment with base and applied for $\mathrm{Pb}^{2+}$ and $\mathrm{Cd}^{2+}$ removal [24]. We decided, based on a report of chemical etching on a glass surface using $\mathrm{HCl}$ [25], to explore if modification under acidic conditions while maintaining structural integrity was possible and what impact this would have on their properties and potential use in remediation. A report dealing with the treatment of naturally occurring clinoptilolites in Cuba using $0.6 \mathrm{M} \mathrm{HCl}$ discovered that milder forms of acid treatment were required as higher concentrations led to the decomposition of the zeolites [26]. We discovered that treatment with concentrated $\mathrm{HCl}$ removes metal ions from the pores leaving the silicon framework intact with the clinoptilolite variety whereas the chabazite ones became amorphous. Structures were assessed on the bases of solidstate ${ }^{29} \mathrm{Si}$ and ${ }^{27} \mathrm{Al}$ NMR, BET measurements, SEM images, and powder X-ray fluorescence and diffraction. Lead removal studies on the clinoptilolite samples suggested differing capacities between the two samples after calcination and deterioration of $\mathrm{Pb}^{2+}$ storage capacity upon modification.

\section{Materials and Methods}

\subsection{Materials:}

The zeolites were generously donated from St Cloud Mining Company and consisted of St Cloud Mining Bowie chabazite (AZLB-Na, -325 mesh), St Cloud Mining Bowie chabazite (AZLB-Ca, -325 mesh), St Cloud Winston clinoptilolite (NM-Ca, -325 mesh), and St Cloud Mining Ash Meadows clinoptilolite (NV-Na, -325 mesh) where AZLB =Arizona Land Basin, NM = New Mexico, NV = Nevada, $\mathrm{Na}$ is the dominant cation, $\mathrm{Ca}$ is the dominant cation. $\mathrm{HCl}(12.1 \mathrm{M})$ and $\mathrm{HNO}_{3}(15.6 \mathrm{M})$ acids were obtained from Fisher. Lead nitrate was obtained from Mallinckrodt Chemical Works.

\subsection{Zeolite Modifications:}

\subsubsection{Calcined Zeolites}

The calcined zeolite samples were obtained by heating the zeolites at $550^{\circ} \mathrm{C}$ for 5 hours under air. After cooling the zeolite, the samples were stored in a desiccator to prevent the absorption of water.

\subsubsection{Hydrochloric Acid Treated Zeolites}

The $\mathrm{HCl}$ acid-treated samples were prepared by refluxing a solution of the acid and zeolite at a ratio of $10 \mathrm{~mL}$ of concentrated $\mathrm{HCl}$ per gram of zeolite. This was based on a procedural modification from the literature [25] and the samples were placed in an oil bath for 10, 20, 30, or 40 minutes and, upon removal, allowed to cool for 20 minutes. The zeolite was quickly filtered off after cooling and washed with water 3 times at a ratio of 5 $\mathrm{mL}$ per gram of zeolite initially used. The zeolite was dried overnight in an oven at $70{ }^{\circ} \mathrm{C}$ and then calcined at $550^{\circ} \mathrm{C}$ in a flow of air for 5 hours. After cooling, the zeolite was stored in a desiccator to prevent the absorption of water.

\subsection{X-ray Diffraction:}

X-ray diffraction spectra of the zeolites were collected using a Scintag XDS 2000 Diffractometer (Scintag Division of Thermo Dearborn, Michigan) using a copper target to generate $X$-rays and a graphite monochromator with a scan range of $5-60^{\circ} 2 \theta$, a step size of $0.020^{\circ}$, a count time of 0.600 seconds, and a step scan rate of $2.0 \mathrm{deg} / \mathrm{min}$. The samples were packed into an aluminum sample plate of dimensions of $30 \mathrm{~mm}$ wide by $90 \mathrm{~mm}$ long by $8 \mathrm{~mm}$ depth. 
The data was analyzed using DMSNT v 1.37 (1994-1998) Scintag Inc. (Division of Thermo Dearborn, Michigan). The spectra were background-subtracted using a manual spline curve fit. Sample phase identification was conducted using QualX2 [27] after the raw data was transformed using PowDLL [28].

2.4 Energy Dispersive Spectroscopy:

EDS/XRF was performed to obtain an elemental composition of the zeolites using a Xenemetrix EX-6600 EDS machine (Migdal HaEmek, Israel) with a rhodium target to generate the X-Rays. Samples were prepared by mixing the zeolite with corn starch at a ratio of 4:1 weight zeolite: corn starch. The mixture was added to an aluminum cup with a diameter of $3 \mathrm{~cm}$ and a depth of $0.75 \mathrm{~cm}$. Once packed by hand pressure, the cup was loaded into a hydraulic press and pressure applied for 1 minute up to 700 psi, once reached the sample was held for 1 minute at 700 psi and then for 1 minute the pressure was released.

\subsection{Surface Area Analysis:}

Surface area analysis was performed using an ASAP 2020 machine made by Micrometrics (Norcross, Georgia). The program used for the analysis was the "5-point BET Analysis" program supplied by the manufacturer. Some modifications were required and consisted of adding parameters from the standard micropore analysis program (from the manufacturer) to the 5 Point BET Program. The samples were degassed at $350^{\circ} \mathrm{C}$ at $1 \mathrm{~mm}$ $\mathrm{Hg}$ for 4 hours and backfilled with nitrogen gas. The BET analysis was performed using nitrogen gas and the micropore analysis was performed using helium gas. Calibration of the machine was checked by running a standard supplied by Micrometrics.

\subsection{Lead Removal Studies:}

An analysis of the amount of lead absorbed or adsorbed by the zeolite was performed using a Buck Scientific Model 200A atomic absorption spectrometer. A Fisher hollow cathode tube for lead analysis was used at an operating current of $10 \mathrm{~mA}$. The detector was set to a wavelength of $283.3 \mathrm{~nm}$ with a slit width of $0.7 \mathrm{~nm}$.

A $335 \mathrm{mg} / \mathrm{L}$ concentrated lead nitrate solution was made using water with a $\mathrm{pH}$ of 4.5 which was adjusted using $\mathrm{HNO}_{3}$ acid. 0.250 grams of previously dried zeolite was added to $150 \mathrm{~mL}$ of the $335 \mathrm{ppm}$ lead nitrate solution and stirred for 5 days at room temperature [29]. After 5 days the solution was centrifuged, the sample was diluted and analysis was performed on the AAS.

\subsection{NMR Study of Zeolite:}

${ }^{27} \mathrm{Al}$ MAS and ${ }^{29} \mathrm{Si}$ MAS NMR analyses of calcined NV-Na and $30 \mathrm{~min} \mathrm{HCl} \mathrm{NV}-\mathrm{Na}$ were performed at ambient temperature on a Varian Infinity-Plus NMR spectrometer equipped with a $6 \mathrm{~mm}$ MAS broadband probe operating at $79.41 \mathrm{MHz}$ for ${ }^{29} \mathrm{Si}, 104.2 \mathrm{MHz}$ for ${ }^{27} \mathrm{Al}$, and $399.75 \mathrm{MHz}$ for ${ }^{1} \mathrm{H}$. Samples were spun at the magic angle at $4 \mathrm{kHz}$. A standard one-pulse was used for all experiments. The ${ }^{29} \mathrm{Si}$ pulse width was $4 \mu \mathrm{s}$, the pulse delay was $120 \mathrm{~s}$, the acquisition length was $20.5 \mathrm{~ms}$, and between 650-700 scans were collected. Exponential multiplication of $100 \mathrm{~Hz}$ was used before the Fourier transform. Chemical shifts were referenced against an external sample of talc at $-98.1 \mathrm{ppm}$ relative to TMS (tetramethylsilane) at $0 \mathrm{ppm}$. The ${ }^{27} \mathrm{Al}$ pulse width was $1 \mu \mathrm{s}$, the pulse delay was $0.2 \mathrm{~s}$, the acquisition length was $2.1 \mathrm{~ms}$, and between 8,000-10,000 scans were collected. Exponential multiplication of $100 \mathrm{~Hz}$ was used prior to the Fourier transform. Chemical shifts were referenced against an external sample of $1 \mathrm{M} \mathrm{Al}\left(\mathrm{NO}_{3}\right)_{3}$ at $0.0 \mathrm{ppm}$.

\subsection{Scanning Electron Microscopy}

SEMs were performed on a Hitachi S4700 Scanning Electron Microscope at a voltage of $15-20 \mathrm{kV}$ and $10-20 \mu \mathrm{A}$.

\subsection{ATR-FTIR}

FTIR was performed on a PerkinElmer Spectrum one (neat samples) with a Perkin Elmer universal ATR sampling attachment. 


\section{Results and Discussion}

\subsection{X-Ray Diffraction}

\subsubsection{Initial Phase Assignment}

The spectra obtained for AZLB-Ca, Fig. 1 and AZLB-Na, Fig. 2 suggests the presence of chabazite if one compares the patterns to that obtained from simulations [30] of singlecrystal X-ray data [21]. In particular, we note the presence of the intense reflections for Miller indices $\left(\begin{array}{lll}1 & 0 & 0\end{array}\right)$ and $\left(\begin{array}{ll}3 & \overline{1} \\ 1\end{array}\right)$ at $2 \theta$ of $9.40^{\circ}$ and $30.40^{\circ}$ respectively which are ascribed to chabazite [30]. These suggest that the samples were dominantly chabazite, however differing ratios of erionite and $\mathrm{AlPO}_{4}-\mathrm{D}$ were also evident in the samples [30,31]. Interestingly, no phases indicative of clinoptilolite, heulandite, or alpha quartz were observed in either sample AZLB-Ca or AZLB-Na, Figs. 1 and 2 respectively.

The X-ray powder spectra for the clinoptilolite samples, NV-Na Fig. 3 and NM-Ca Fig. 4 also contained large differences. Evidence for clinoptilolites is in the presence of reflections at $9.88^{\circ}, 11.19^{\circ}$ and $22.49^{\circ}$ in $2 \theta$ ascribable to the $(020),(200)$ and (3 30$)$ Miller indices respectively $[30,32,33]$. In the case of the calcined NV-Na sample (Fig. 3) signals for these peaks are quite intense and the sample appears to be quite pure. There was a match for clinoptilolite-Na (card [00-900-1391]) at a FoM of 0.75 determined using QualX2 [27]. Raw data from the diffractometer were converted with PowDLL [28] for use with the QualX2 program. In the case of NM-Ca (Fig. 4), the most intense peak is located at about a $2 \theta$ of $26.6^{\circ}$ and the program QualX2 [27] could not find a match to clinoptilolite. This is probably because this calcined NM-Ca sample is mostly alpha quartz which has its most intense reflection at a $2 \theta$ of $26.65^{\circ}$ due to the $\left(\begin{array}{lll}1 & 0 & 1\end{array}\right)$ Miller phase [34]. There is some evidence of clinoptilolite in the sample judging by small peaks at the $2 \theta$ angles mentioned above but it is clearly not the dominant constituent. No chabazite or erionite species were observed in either sample NV-Na or NM-Ca.

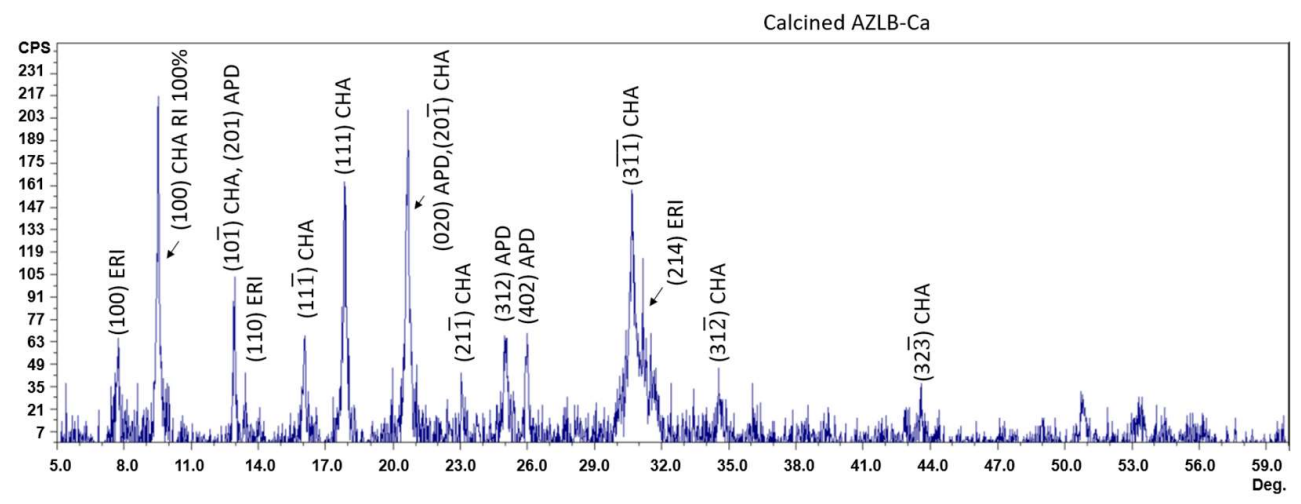

Figure 1. The XRD pattern of calcined AZLB-Ca. Abbreviations ERI=erionite, CHA=chabazite, $\mathrm{APD}=\mathrm{AlPO}_{4}-\mathrm{D}, \mathrm{RI}=$ Relative intensity. Identification based on data in reference [30].

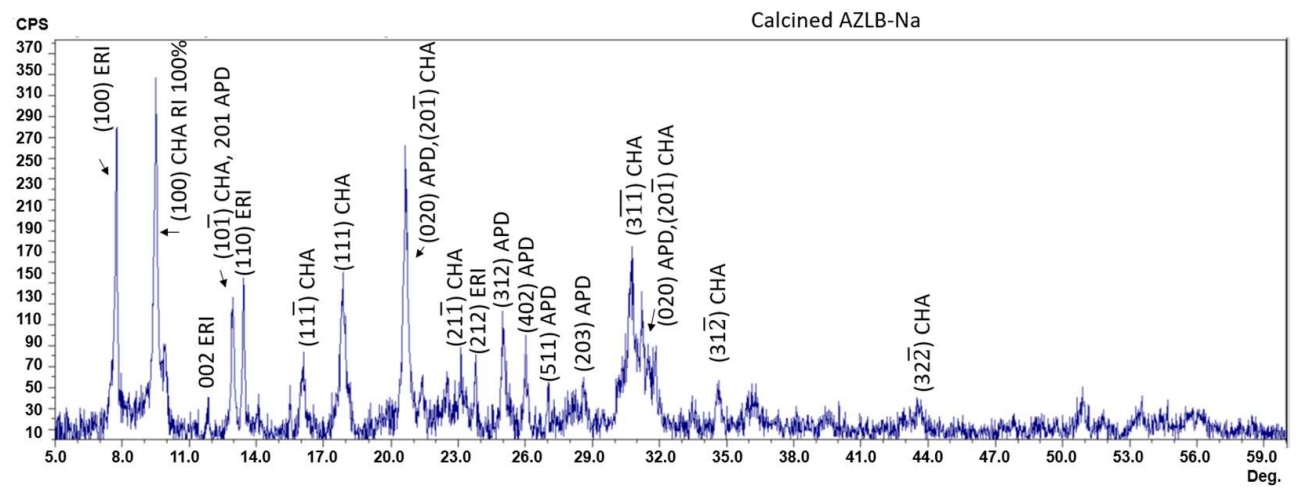


Figure 2. The XRD pattern of calcined AZLB-Na. Abbreviations ERI=erionite, $\mathrm{CHA}=$ chabazite, $\mathrm{APD}=\mathrm{AlPO}_{4}-\mathrm{D}, \mathrm{RI}=$ Relative intensity. Identification based on data in reference [30].

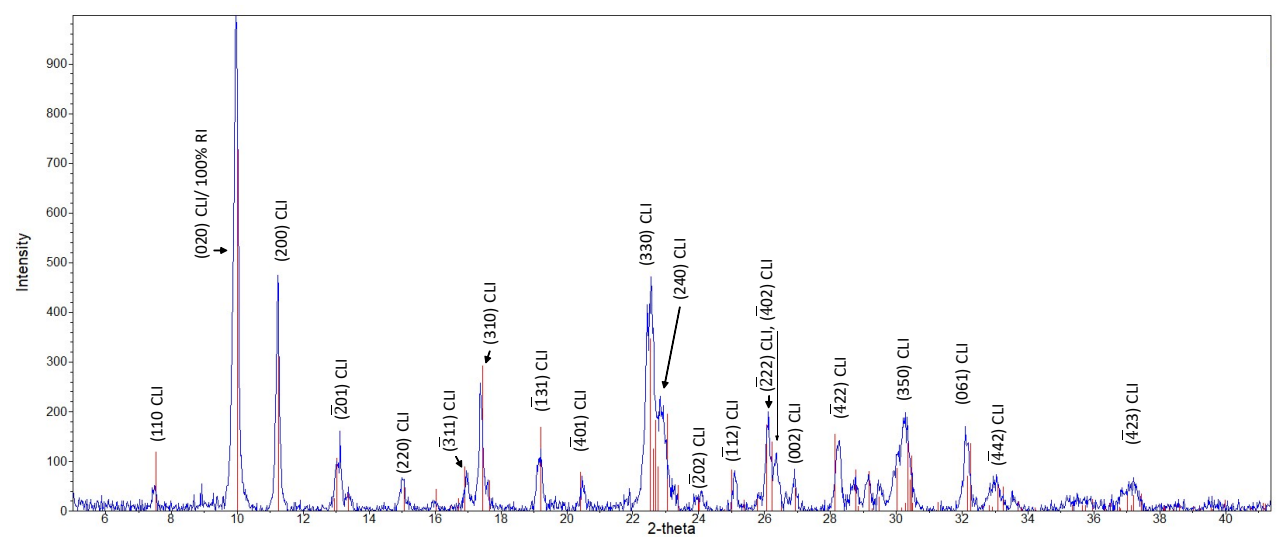

Figure 3. The XRD pattern of calcined NV-Na. Abbreviations, CLI = clinoptilolite, RI= relative intensity. Identification based on data in reference [30]. Solid vertical lines represent card [00-9001391] clinoptilolite-Na at a FoM of 0.75 as determined using QualX [27]. Raw data converted with PowDLL [28].

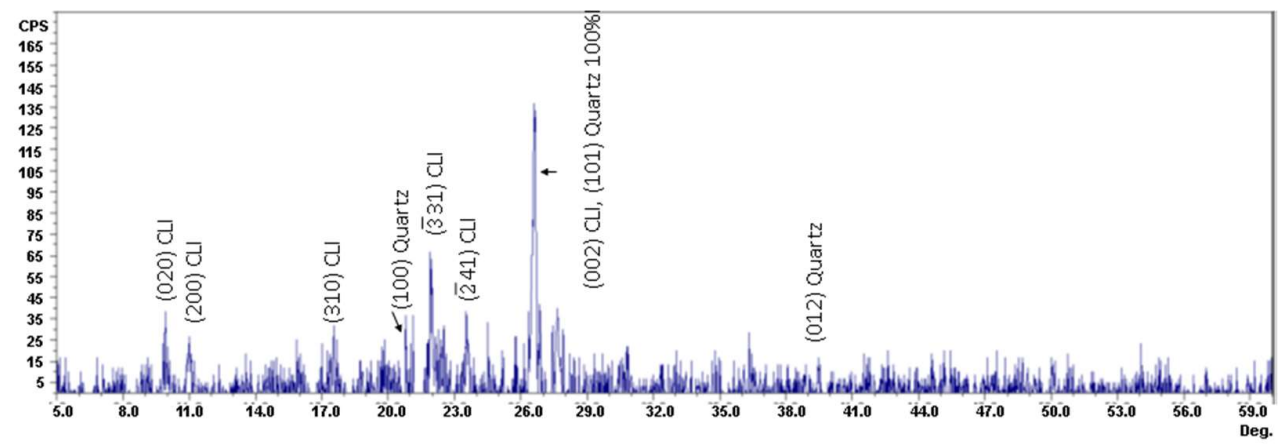

Figure 4. The XRD pattern of calcined NM-Ca. Abbreviations, CLI = clinoptilolite, RI=relative intensity. Identification based on data in reference [30].

The AZLB-Na and AZLB-Ca zeolites lost all crystallinity when boiled in $\mathrm{HCl}$ acid for 30 minutes which is demonstrated by the loss of all sharp reflections and the spectra appearing as broad bumps (Figs. 5 and 6) as a result of random scattering due to an amorphous material. In contrast, the NV-Na and NM-Ca zeolites did not lose all crystallinity during the boiling process in $\mathrm{HCl}$ acid (Figs. 7 and 8, respectively). This is conclusive evidence of the instability of these chabazites subjected to $\mathrm{HCl}$ modification and the inherent stability of the clinoptilolites as evident in the 30 min $\mathrm{HCl} \mathrm{NV-Na,} \mathrm{Fig.} \mathrm{7,} \mathrm{card} \mathrm{[00-900-}$ 1393] clinoptilolite-Na at a FoM of 0.66, and $30 \mathrm{~min} \mathrm{HCl}$ NM-Ca, Fig. 8, card [00-901-4410] boggsite [35] of formula Ca3.4O ${ }_{70.76} \mathrm{Si}_{24}$ at a FoM of 0.77, both determined using QualX2 [27]. In particular, NM-Ca registered the least change possible because it is mostly composed of alpha quartz, Fig. 8. 


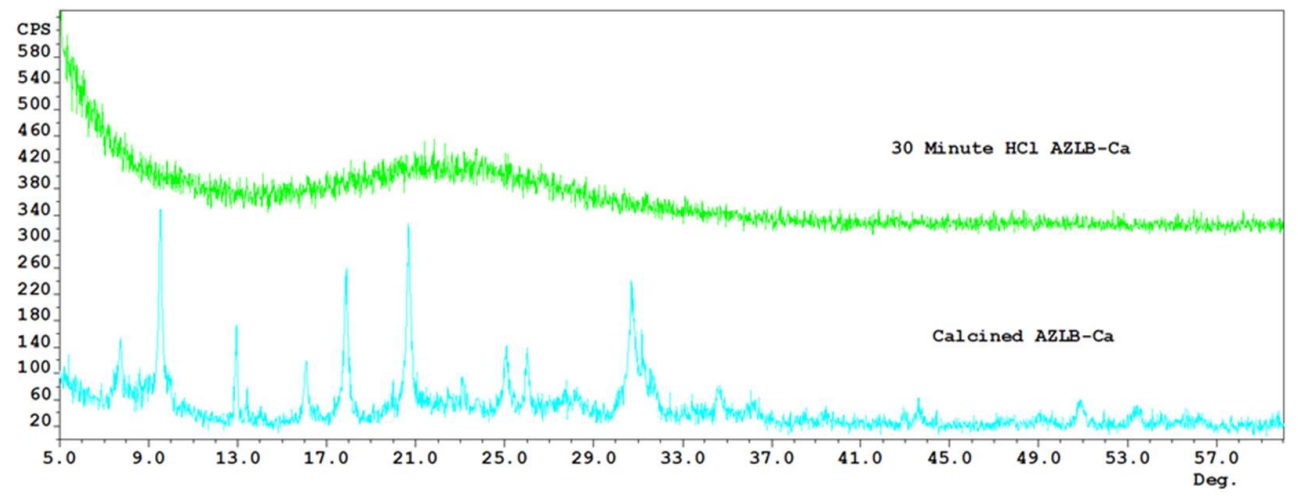

Figure 5. The XRD patterns of calcined AZLB-Ca and 30 minute $\mathrm{HCl}$ AZLB-Ca.

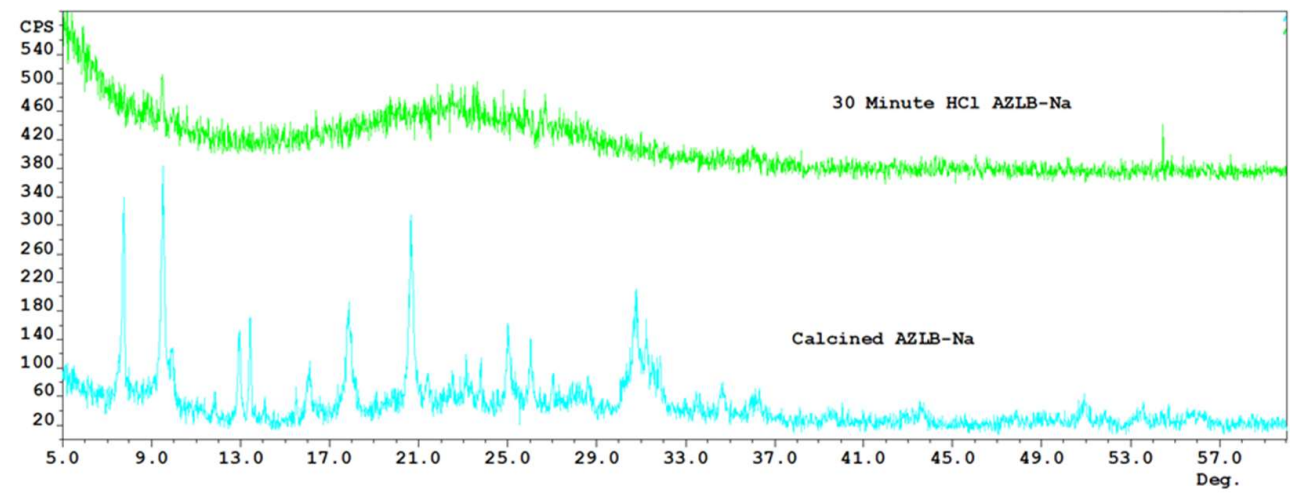

Figure 6. The XRD patterns of calcined AZLB-Na and 30 minute $\mathrm{HCl}$ AZLB-Na.

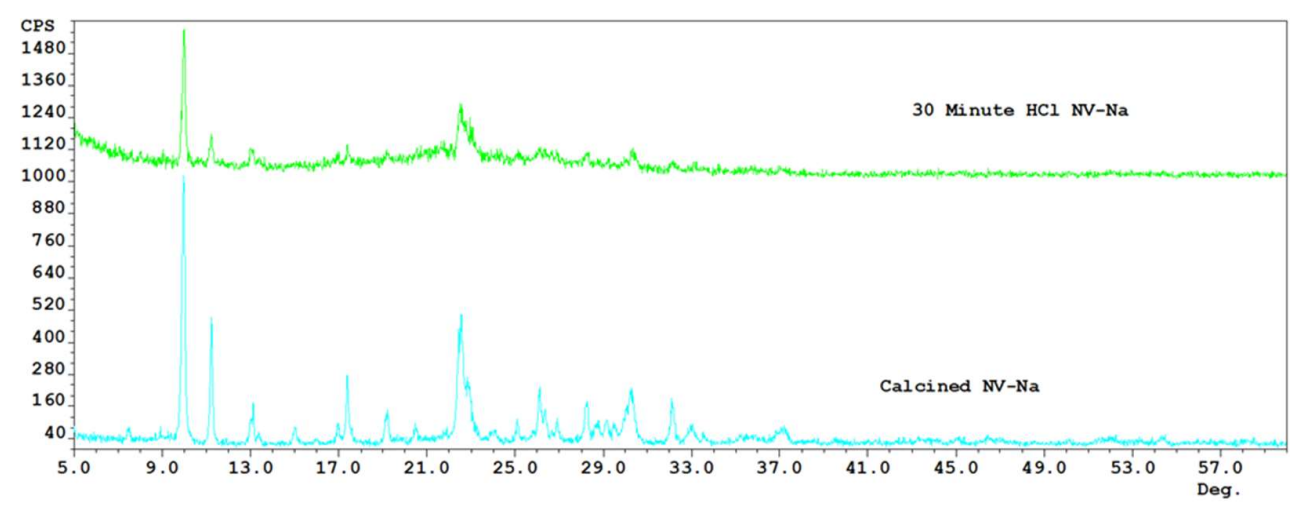

Figure 7. The XRD patterns of Calcined NV-Na and the 30 minute $\mathrm{HCl}$ NV-Na.

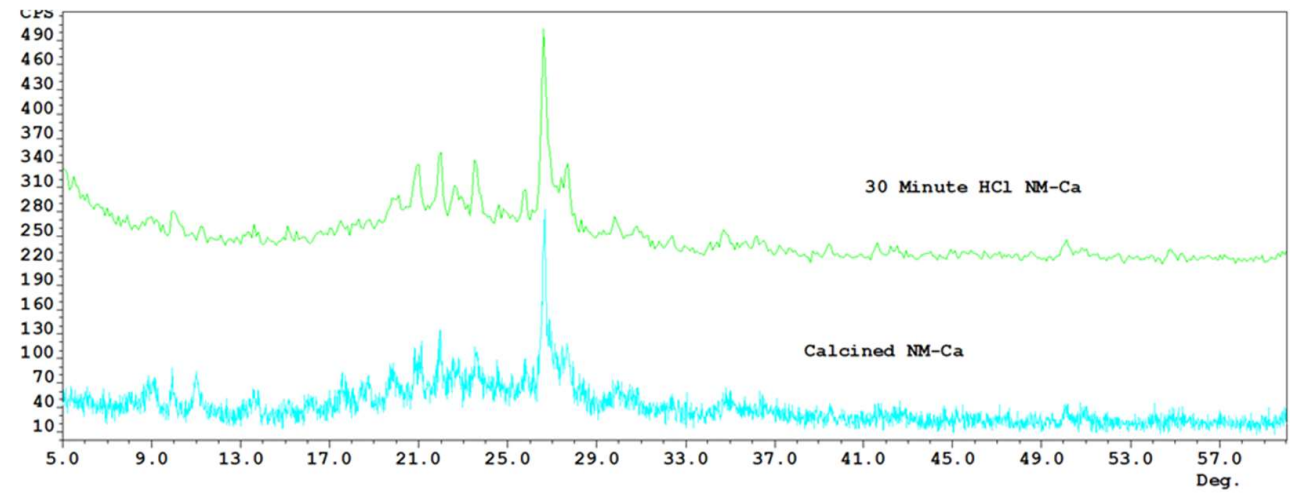


Figure 8. The XRD patterns of Calcined NM-Ca and 30 minute $\mathrm{HCl} \mathrm{NM-Ca.}$

\subsection{Surface Area Analysis}

Based on the fact that the chabazite samples lost crystallinity upon treatment with conc. $\mathrm{HCl}$, we only conducted surface area analyses on the clinoptilolite samples. Thus $\mathrm{NM}-\mathrm{Ca}$ and $\mathrm{NV}-\mathrm{Na}$ were both subjected to boiling concentrated $\mathrm{HCl}$ acid for a varying amount of time from 10-40 minutes as listed with the surface area analysis results (Table 1). This indicated that 30-minute etching of the zeolite produced the highest surface area with 40-minute etching resulting in a decrease in the surface area which is likely due to the acid collapsing some of the crystalline structure. Therefore, in this case, the optimum time for boiling the clinoptilolite zeolite in $\mathrm{HCl}$ acid is 30 minutes. In the case of $\mathrm{NV}-\mathrm{Na}$, the surface area increased from 19 to $158 \mathrm{~m}^{2} / \mathrm{g}$ and the pore volume increased from 0.04 $\mathrm{cm}^{3} / \mathrm{g}$ to $0.12 \mathrm{~cm}^{3} / \mathrm{g}$. The NM-Ca increased in surface area from 20 to $111 \mathrm{~m}^{2} / \mathrm{g}$ and the pore volume increased from 0.04 to $0.10 \mathrm{~cm}^{3} / \mathrm{g}$.

The values for the micropore, mesopore, and external surface areas provide valuable insight into what is happening during the etching process, Tables 1 and 2 . There is a dramatic increase in micropore area of the $\mathrm{HCl}$ acid-etched zeolites, 4.800 to $94.99 \mathrm{~m}^{2} / \mathrm{g}$ for calcined NV-Na to $30 \mathrm{~min} \mathrm{HCl} \mathrm{NV-Na} \mathrm{and} 2.730$ to $55.15 \mathrm{~m}^{2} / \mathrm{g}$ for calcined NM-Ca to 30 min HCL NM-Ca, suggesting that either new micropores are forming and/or the existing micropores are being deepened increasing their surface area. In the case of the calcined NM-Ca sample versus the 10-Min $\mathrm{HCl} \mathrm{NM-Ca} \mathrm{sample,} \mathrm{Table} \mathrm{2,} \mathrm{the} 10 \mathrm{~min} \mathrm{HCl}$ NM-Ca sample has a smaller average micropore diameter going from 4.584 to $4.388 \AA$ and this likely represents new micropores being formed thus lowering the average value for the micropore diameter. The $30 \mathrm{~min} \mathrm{HCl} \mathrm{NM}-\mathrm{Ca}$ sample seems to reach a maximum average micropore diameter of $4.597 \AA$ before declining in the $40 \mathrm{~min} \mathrm{HCl} \mathrm{NM-Ca}$ sample to $4.588 \AA$ which is probably due to the crystallinity of the zeolite collapsing based on the loss of surface area of the sample, see Table 1 . In contrast, NV-Na appears less stable to $\mathrm{HCl}$ treatment and the average micropore diameter increases from 4.586 to $4.600 \AA$ for calcined $\mathrm{NV}-\mathrm{Na}$ to $30 \mathrm{~min} \mathrm{HCl} \mathrm{NV}-\mathrm{Na}$ respectively.

In the case of mesopores, calcined NV-Na has a value of $91.00 \AA$ which decreases to $31.06 \AA$ in the $10 \mathrm{~min} \mathrm{HCl} \mathrm{NV-Na} \mathrm{sample.} \mathrm{This} \mathrm{is} \mathrm{attributable} \mathrm{to} \mathrm{the} \mathrm{formation} \mathrm{of} \mathrm{new}$ mesopores thus lowering the average diameter of mesopores. The same trend is observed with the calcined NM-Ca sample which has an initial average mesopore diameter of 93.71 (calcined NM-Ca) and changes to $40.31 \AA$ (10 min HCl NM-Ca) sample. In the case of the NM-Ca zeolite, the average mesopore diameter continues to become lower with longer treatment in $\mathrm{HCl}$ acid, however, the $\mathrm{NV}-\mathrm{Na}$ zeolite reaches equilibrium around a $32 \AA$ average mesopore diameter (Table 2).

Table 1. The surface area analysis measurements for calcined and $\mathrm{HCl}$ etched zeolites.

\begin{tabular}{|c|c|c|c|c|c|}
\hline Sample & $\begin{array}{c}5 \text { Point BET Surface } \\
\text { area }\left(\mathrm{m}^{2} / \mathrm{g}\right)\end{array}$ & $\begin{array}{l}\text { Pore Volume } \\
\qquad\left(\mathrm{cm}^{3} / \mathrm{g}\right)\end{array}$ & $\begin{array}{l}\text { Micropore Volume } \\
\qquad\left(\mathrm{cm}^{3} / \mathrm{g}\right)\end{array}$ & $\begin{array}{l}\text { Micropore } \\
\text { Area }\left(\mathrm{m}^{2} / \mathrm{g}\right)\end{array}$ & $\begin{array}{c}\text { External Surface } \\
\text { Area }\left(\mathrm{m}^{2} / \mathrm{g}\right)\end{array}$ \\
\hline NV-Na Calcined & $19.0(4)$ & 0.04 & 0.002 & 4.8 & 14.23 \\
\hline 10 min $\mathrm{HCl} \mathrm{NV}-\mathrm{Na}$ & $147(6)$ & 0.11 & 0.049 & 93.28 & 52.05 \\
\hline $20 \mathrm{~min} \mathrm{HCl} \mathrm{NV}-\mathrm{Na}$ & $141(6)$ & 0.11 & 0.043 & 81.43 & 59.87 \\
\hline $30 \mathrm{Min} \mathrm{HCl}$ NV-Na & $158(7)$ & 0.12 & 0.051 & 94.99 & 63.15 \\
\hline $40 \mathrm{~min} \mathrm{HCl} \mathrm{NV-Na}$ & $138(6)$ & 0.11 & 0.041 & 75.06 & 63.49 \\
\hline NM-Ca Calcined & $20.0(1)$ & 0.04 & 0.001 & 2.73 & 17.27 \\
\hline $10 \mathrm{~min} \mathrm{HCl} \mathrm{NM}-\mathrm{Ca}$ & $82.0(3)$ & 0.08 & 0.021 & 38.71 & 43.36 \\
\hline $20 \mathrm{~min} \mathrm{HCl} \mathrm{NM}-\mathrm{Ca}$ & $89.0(3)$ & 0.08 & 0.022 & 41.61 & 47.75 \\
\hline $30 \mathrm{~min} \mathrm{HCl} \mathrm{NM}-\mathrm{Ca}$ & $111(4)$ & 0.1 & 0.029 & 55.15 & 56.22 \\
\hline
\end{tabular}


$\begin{array}{llllll}40 \mathrm{~min} \text { HCl NM-Ca } & 101(4) & 0.08 & 0.028 & 53.53 & 48.28\end{array}$

Table 2. The average mesopore and micropore diameter.

\begin{tabular}{|c|c|c|}
\hline Sample & $\begin{array}{c}\text { Average Micropore } \\
\text { Diameter (Å) }\end{array}$ & $\begin{array}{c}\text { Average Mesopore } \\
\text { Diameter (Å) }\end{array}$ \\
\hline NV-Na Calcined & 4.586 & 91.00 \\
\hline 10 min $\mathrm{HCl} \mathrm{NV}-\mathrm{Na}$ & 4.597 & 31.06 \\
\hline $20 \mathrm{~min} \mathrm{HCl}$ NV-Na & 4.591 & 32.44 \\
\hline $30 \mathrm{Min} \mathrm{HCl} \mathrm{NV}-\mathrm{Na}$ & 4.600 & 31.72 \\
\hline 40 min $\mathrm{HCl}$ NV-Na & 4.598 & 32.95 \\
\hline NM-Ca Calcined & 4.584 & 93.71 \\
\hline $10 \mathrm{~min} \mathrm{HCl} \mathrm{NM}-\mathrm{Ca}$ & 4.388 & 40.31 \\
\hline 20 min $\mathrm{HCl}$ NM-Ca & 4.584 & 39.62 \\
\hline $30 \mathrm{~min} \mathrm{HCl} \mathrm{NM}-\mathrm{Ca}$ & 4.597 & 36.36 \\
\hline $40 \mathrm{~min} \mathrm{HCl}$ NM-Ca & 4.588 & 34.63 \\
\hline
\end{tabular}

\subsection{X-Ray Fluorescence/EDS}

The NM-Ca zeolite has a much greater mole percentage concentration of Ca $(6.31 \%)$ compared to that for NV-Na (1.14\%) while containing less $\mathrm{Na},(0.10$ to 0.25 respectively), clearly justifying the label, Table 3. There is also more Fe in NM-Ca compared to NV-Na ( 2.67 to $0.79 \%$ respectively) and correspondingly less $\mathrm{Si}$ (76.26 to $84.36 \%$ respectively). The $X$-ray fluorescence data results in Table 3 show by way of the reduction in molar percentage concentrations that etching the zeolites in concentrated $\mathrm{HCl}$ acid effectively removes sodium, calcium, potassium, magnesium, iron, and aluminum while it appears the silicon remained mostly unaffected. Table 4 lists the weight percentage data supplied by the

Table 3. The XRF data for zeolites in mole \%.

$\begin{array}{lccccccccc}\text { Experimental Run } & \mathbf{N a} & \mathbf{C a} & \mathbf{K} & \mathbf{M g} & \mathbf{F e} & \mathbf{A l} & \mathbf{S i} & \mathbf{P} & \text { Si:Al }_{2} \text { Ratio } \\ \text { NV-Na } & 0.25 \pm 0.08 & 1.14 \pm 0.04 & 3.34 \pm 0.08 & 0.30 \pm 0.08 & 0.79 \pm 0.01 & 9.27 \pm 0.24 & 84.36 \pm 0.70 & 0.442 \pm 0.08 & 4.55 \\ \text { 30 Min NV-Na } & 0.02 \pm 0.04 & 0.05 \pm 0.01 & 0.30 \pm 0.02 & 0.16 \pm 0.04 & 0.04 \pm 0.002 & 4.16 \pm 0.11 & 95.04 \pm 0.49 & 0.17 \pm 0.03 & 11.42 \\ \text { NM-Ca } & 0.10 \pm 0.04 & 6.31 \pm 0.11 & 4.29 \pm 0.10 & 0.52 \pm 0.05 & 2.67 \pm 0.04 & 9.51 \pm 0.17 & 76.26 \pm 0.46 & 0.27 \pm 0.04 & 4.01 \\ \text { 30 Min NM-Ca } & 0.04 \pm 0.04 & 0.42 \pm 0.04 & 2.54 \pm 0.08 & 0.17 \pm 0.05 & 0.07 \pm 0.002 & 4.71 \pm 0.13 & 91.83 \pm 0.56 & 0.17 \pm 0.04 & 9.75\end{array}$

manufacturer [36] and that obtained by converting the molar percentages in Table 3 to weight percentages. This requires the assumption that only the ions listed in Table 3 were present and that they are present in the zeolite in the oxide form indicated in the table. Additionally, XRF is not good at determining very low concentrations. However, there are large differences in the weight percentages between our determinations and those determined by the manufacturer. This may well be due to natural variation in the samples used in the studies. Our determinations of the concentrations of $\mathrm{Al}_{2} \mathrm{O}_{3}$ would appear to be much lower whereas those for $\mathrm{SiO}_{2}$ are higher compared to those listed by the manufacturer. However, this does correlate with the X-ray powder diffraction pattern where quartz was found in NM-Ca, Fig. 8. On this basis, NV-Na is composed mostly of $\mathrm{K}_{2} \mathrm{O}$, $\mathrm{Al}_{2} \mathrm{O}_{3}$, and $\mathrm{SiO}_{2}$ in contrast to $\mathrm{NM}-\mathrm{Ca}$ where $\mathrm{CaO}, \mathrm{K}_{2} \mathrm{O}, \mathrm{Fe}_{2} \mathrm{O}_{3}, \mathrm{Al}_{2} \mathrm{O}_{3}$, and $\mathrm{SiO}_{2}$ are the major contributors. This calculation allows for a stoichiometric formula for $\mathrm{NV}-\mathrm{Na}$ of $[\mathrm{Na} 2 \mathrm{O}]_{0.01}[\mathrm{CaO}]_{0.11}\left[\mathrm{~K}_{2} \mathrm{O}\right]_{0.27}[\mathrm{MgO}]_{0.02}\left[\mathrm{Fe}_{2} \mathrm{O}_{3}\right]_{0.11}\left[\mathrm{P}_{2} \mathrm{O}_{5}\right]_{0.05}\left[\mathrm{Al}_{2} \mathrm{O}_{3}\right]_{0.80}\left[\mathrm{SiO}_{2}\right]_{8.63}$ and NM-Ca of $[\mathrm{CaO}]_{0.60}\left[\mathrm{~K}_{2} \mathrm{O}\right]_{0.34}[\mathrm{MgO}]_{0.04}\left[\mathrm{Fe}_{2} \mathrm{O}_{3}\right]_{0.36}\left[\mathrm{Al}_{2} \mathrm{O}_{3}\right]_{0.83}\left[\mathrm{SiO}_{2}\right]_{7.79}$.

Table 4. The weight percentages from our calculated data and that of the manufacturer.

\begin{tabular}{|c|c|c|c|c|c|c|}
\hline \multirow[b]{2}{*}{ Experimental } & \multirow[b]{2}{*}{ mole \% } & \multirow[b]{2}{*}{ Formula } & \multicolumn{2}{|c|}{ NV-Na } & \multicolumn{2}{|c|}{ NM-Ca } \\
\hline & & & Calculated & Manufacturer & Calculated & Manufacturer \\
\hline $\mathrm{Na}$ & 0.10 & $\mathrm{Na}_{2} \mathrm{O}$ & 0.13 & 3.5 & 0.05 & 0.3 \\
\hline
\end{tabular}




$\begin{array}{ccccccc}\mathrm{Ca} & 6.31 & \mathrm{CaO} & 1.09 & 0.8 & 6.02 & 3.4 \\ \mathrm{~K} & 4.29 & \mathrm{~K}_{2} \mathrm{O} & 2.68 & 3.8 & 3.44 & 3.2 \\ \mathrm{Mg} & 0.52 & \mathrm{MgO} & 0.21 & 0.4 & 0.36 & 1.4 \\ \mathrm{Fe} & 2.67 & \mathrm{Fe}_{2} \mathrm{O}_{3} & 1.07 & 0.7 & 3.63 & 1.6 \\ \mathrm{Al} & 9.51 & \mathrm{Al}_{2} \mathrm{O}_{3} & 8.04 & 11.9 & 8.25 & 11.9 \\ \mathrm{Si} & 76.26 & \mathrm{SiO}_{2} & 86.25 & 69.1 & 77.94 & 64.9 \\ \mathrm{P} & 0.27 & \mathrm{P}_{2} \mathrm{O}_{5} & 0.53 & & 0.33 & >0.05 \\ & & \mathrm{MnO} & & 0.02 & & \mathbf{8 6 . 7}\end{array}$

${ }^{\mathrm{a}}$ reference [36]

\subsection{Lead Removal Study}

We were interested in comparing the lead absorption and/or adsorption capacities between the calcined material and the $30 \mathrm{~min} \mathrm{HCl}$ modified clinoptilolites which had more micropores and a larger surface area. First, AZLB-Na and AZLB-Ca removed 2.05(27) and 2.00(11) meq/g of $\mathrm{Pb}^{2+}$ and this was slightly more than the removal with the clinoptilolites as evident in Table 5. This difference, i.e., better removal with chabazites than clinoptilolites was previously noted [24]. Two other natural clinoptilolites report an ion exchange of $0.730 \mathrm{meq} / \mathrm{g} \mathrm{Pb}^{2+}[37]$, and $0.433 \mathrm{meq} / \mathrm{g} \mathrm{Pb}^{2+}[38]$. NV-Na calcined is significantly better at the ion exchange of $\mathrm{Pb}^{2+}$ than these natural clinoptilolites at $1.50 \pm 0.17$ meq/g, Table 5. NM-Ca, $30 \mathrm{~min} \mathrm{HCl} \mathrm{NV-Na,} \mathrm{and} 30 \mathrm{~min} \mathrm{HCl} \mathrm{NM-Ca} \mathrm{s} \mathrm{are} \mathrm{not} \mathrm{efficient} \mathrm{at}$ the ion exchange of $\mathrm{Pb}^{2+}$ with ion exchanges of $0.27,0.41$, and 0.06 respectively, Table 5 .

The results of this lead removal study prove that treating the zeolite in $\mathrm{HCl}$ acid decreases the ability of the zeolite to remove lead ions from the solution. Theoretically, if the removal of lead was based on ion exchange, the $\mathrm{Pb}^{2+}$ ion would likely exchange with $\mathrm{K}^{+}$ due to the radius of $\mathrm{Pb}^{2+}$ being $133 \mathrm{pm}$ versus $\mathrm{K}^{+}$having a radius of $137 \mathrm{pm}$ [39]. However, if lead ions are exchanged solely with $\mathrm{K}^{+}$ions, we would have expected $\mathrm{NM}$-Ca to have a higher rate of removal than NV-Na. The increase in uptake by NV-Na may be attributed to the fact that it contains less quartz than NM-Ca, thus a more clinoptilolite structure, as was evident in the X-ray powder diffraction spectra, Figs. 3 and 4.

Table 5. The $\mathrm{Pb}^{2+}$ removal by the zeolites at a time of 5 days at $35^{\circ} \mathrm{C}$. [13]

$\begin{array}{cc}\text { Sample } & \text { Meq/g of } \mathbf{P b}^{2+}(\mathbf{3} \text { samples }) \\ \text { AZLB-Na } & 2.05(27) \\ \text { AZLB-Ca } & 2.00(11) \\ \text { NV-Na calcined } & 1.50(17) \\ \text { NM-Ca calcined } & 0.27(14) \\ 30 \mathrm{Min} \mathrm{HCl} \text { NV-Na } & 0.41(23) \\ 30 \mathrm{Min} \mathrm{HCl} \mathrm{NM-Ca} & 0.06(9)\end{array}$

In order to increase the lead ion uptake, the zeolites were stirred in a $1 \mathrm{M} \mathrm{KCl}$ solution at $25^{\circ} \mathrm{C}$ for 5 days. They were then filtered and washed with water until the filtrate was clear of chloride ions which was monitored by tests with silver nitrate solution [40]. After drying and calcining at $550{ }^{\circ} \mathrm{C}$ for 5 hours, these treated zeolites were tested similarly for their ability to remove lead ions from polluted water. 
Table 6. The $\mathrm{Pb}^{2+}$ removal by the $\mathrm{K}^{+}$charged zeolites at a time of 5 days at $35^{\circ} \mathrm{C}$.

$$
\begin{gathered}
\text { Sample } \\
\mathrm{K}^{+} \text {charged NV-Na } \\
\mathrm{K}^{+} \text {charged NM-Ca } \\
\mathrm{K}^{+} \text {charged } 30 \text { Min } \mathrm{HCl} \mathrm{NV-Na} \\
\mathrm{K}^{+} \text {charged } 30 \mathrm{Min} \mathrm{HCl} \mathrm{NM-Ca}
\end{gathered}
$$

The results listed in Table 6 show that charging NV-Na with $\mathrm{KCl}$ decreased its ability to remove lead as there was a significant decrease in the quantities removed, 1.50(17) for $\mathrm{NV}-\mathrm{Na}$ calcined to $0.84(5) \mathrm{meq} / \mathrm{g}$ for the $\mathrm{K}^{+}$charged sample. There were no significant differences with the other zeolites as this method did not have high enough precision as is evident in the data in Tables 5 and 6. However, charging these zeolites with potassium ions by stirring in a potassium chloride solution was ineffective at increasing the zeolite's ability to remove $\mathrm{Pb}^{2+}$ ions from the solution. It is also possible given the high percentage concentration of $\mathrm{Si}$ in the two zeolites, removal of the $\mathrm{Fe}^{3+}$ and $\mathrm{Al}^{3+}$ ions result in a more electrically neutral species thus reducing the capacity for ion exchange.

\section{$3.5^{27} \mathrm{Al} \mathrm{NMR}$}

Aluminum NMR is very sensitive to the geometry with 6-coordinate species resonating around 4-11 ppm and 4-coordinate downfield in the range 55-66 ppm depending on the nature of the aluminosilicate species [41]. Only one signal at 55 ppm belonging to tetrahedral aluminum species was evident in the ${ }^{27} \mathrm{Al}$ spectrum of a clinoptilolite found in Cuba [26]. As is evident in Fig. 9, which displays the ${ }^{27} \mathrm{Al}$ NMR of the calcined NV-Na sample, the $\mathrm{Al}$ in that sample is composed mainly of 4-coordinate $\mathrm{Al}$ species as the spectrum consists mainly of a large single resonance at $54.49 \mathrm{ppm}$. A much smaller quantity is in the octahedral conformation which corresponds to the peak at $2.60 \mathrm{ppm}$. Applying a framework equation [41] which equates the position of the ${ }^{27} \mathrm{Al}$ isotropic chemical shift to the angles on the $\mathrm{Al}$ (i.e., $\left.\delta_{\mathrm{Al}}=132-(0.5 \cdot \angle \mathrm{Al}-\mathrm{O}-\mathrm{Si})\right)$ would suggest a mean $\angle \mathrm{Al}-\mathrm{O}-\mathrm{Si}$ of $155^{\circ}$. However, this derivation is not valid for zeolites with a high percentage of $\mathrm{Si}$ as other factors also pertain [42].

Subjecting the zeolite to $\mathrm{HCl}$ resulted in changes in the ${ }^{27} \mathrm{Al} \mathrm{NMR}$ spectrum as evident in Fig. 10. The peak for the 4-coordinate species in calcined NV-Na shifts from 54.99 to a broad peak with peaks at 53.96 and 59.64 ppm for the $30 \mathrm{~min} \mathrm{HCl} \mathrm{NV-Na.} \mathrm{Additionally,}$ there is a slight shift in the octahedral resonance from 2.60 to $2.03 \mathrm{ppm}$. This indicates that the ratio of tetrahedral to octahedral aluminum has changed, however, it is unknown whether this is due to conversion or the dissolution of one of the forms following $\mathrm{HCl}$ treatment [19]. 


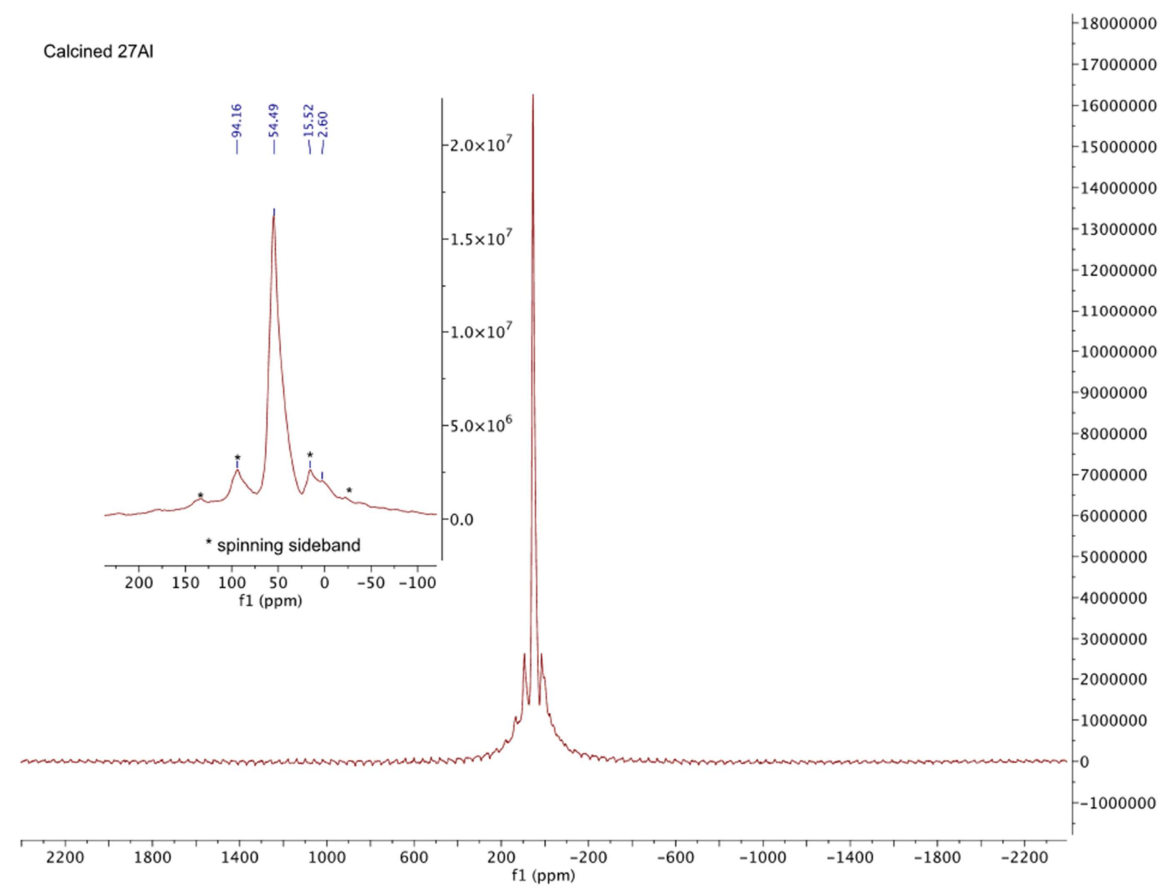

Figure 9. The ${ }^{27} \mathrm{Al} \mathrm{NMR}$ of calcined NV-Na externally referenced to $1 \mathrm{M} \mathrm{Al}\left(\mathrm{NO}_{3}\right)_{3}$ at $0.0 \mathrm{ppm}$.

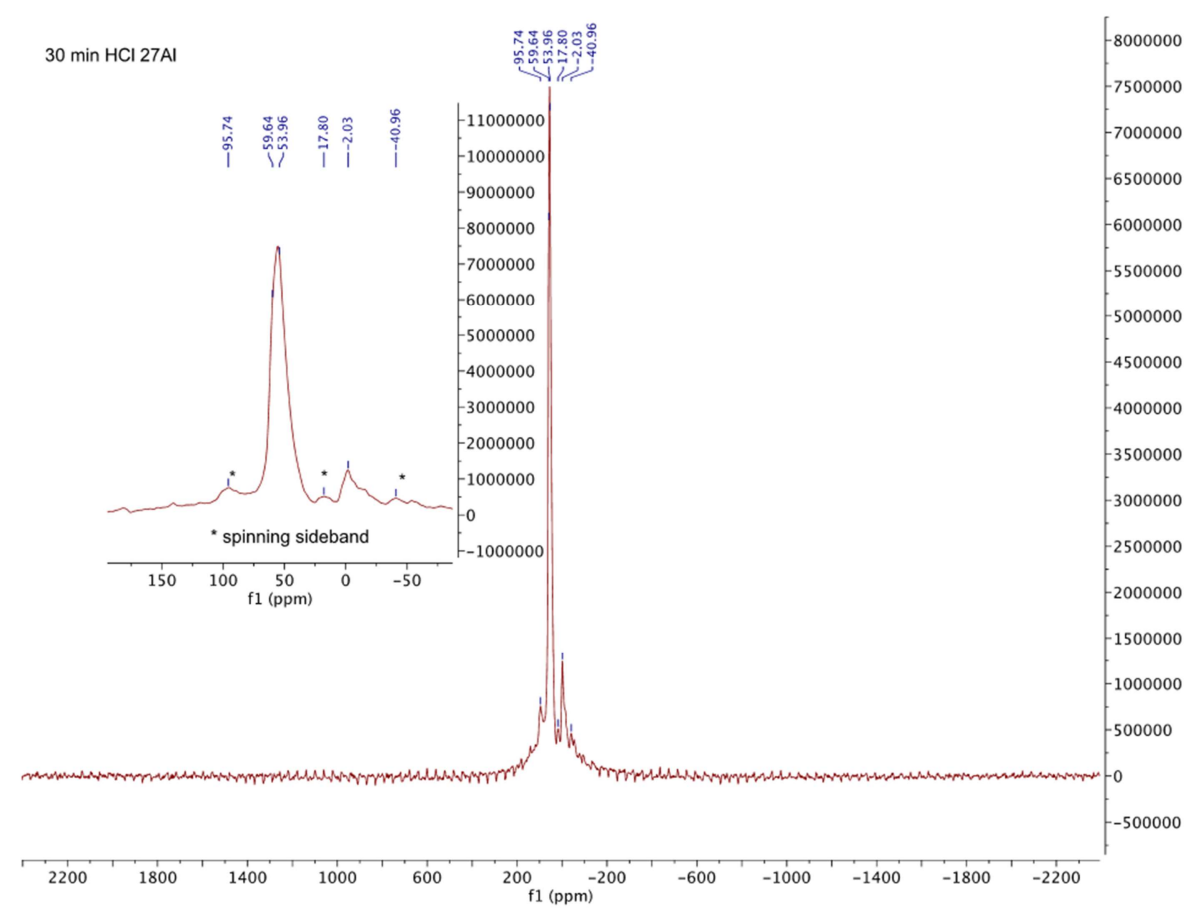

Figure 10. The ${ }^{27} \mathrm{Al} \mathrm{NMR}$ of $30 \mathrm{~min} \mathrm{HCl} \mathrm{NV}$-Na externally referenced to $1 \mathrm{M} \mathrm{Al}\left(\mathrm{NO}_{3}\right)_{3}$ at $0.0 \mathrm{ppm}$. 


\subsubsection{Calcined NV-Na}

The ${ }^{29} \mathrm{Si}$ NMR spectrum of clinoptilolite has been reported to consists of peaks at $-112.8,-106.9$, and -100.6 ppm with the peak at -106.9 having the highest intensity [43]. The spectrum for calcined NV-Na contains many signals as listed in Fig. 11, but the one with the most area occurs at -106.02 ppm (27.12\%). Peaks at $-112.14(13.46 \%)$ and $-100.1(23.43 \%)$ ppm are also obtained and these are probably from the clinoptilolite regions within calcined NV-Na. Peaks at -95.99 (19.56\%), -101.11 (2.48\%), -108.58 (13.90\%) ppm are also evident in the deconvoluted analysis, Fig. 10. The peak at -95.99 ppm may be either due to $\mathrm{SiOH}$ and $\mathrm{Si}(\mathrm{OH})_{2}$ groups as $\mathrm{Si}$ resonances for these groups lie in this range [43] or related to the presence of $\mathrm{Fe}^{3+}$ complexes rather than $\mathrm{Al}^{3+}$ [26]. Studies on a natural clinoptilolite from Cuba reported peaks and area percentages of $-94.90(5.7 \%),-97.8(2.3 \%),-100.90$ $(34 \%),-106.90(45.3 \%)$ and $-112.70(13.7 \%)$ [26]. These peaks are very close in position and area to that ascribed to a heulandite zeolite which has the following peaks and areas, $-93.44(4.25 \%),-98.44$ (31.26\%), -104.63 (56.11\%), and -111.41 (8.37\%) [44]. However, in our NV-Na sample, the peaks at $-101.11(2.48 \%)$ and $-108.58(13.90 \%)$ are probably due to impurities with the one at $-108.58 \mathrm{ppm}$ possibly due to regions of pure $\left(\mathrm{SiO}_{2}\right)_{\mathrm{n}}$ [45].

The Si:Al ratio was calculated from the ${ }^{29} \mathrm{Si}$ MAS NMR data using Equation 1 [43].

$$
\frac{S i}{A l}=\frac{\sum_{0}^{4} I_{S i(n A l)}}{\sum_{0}^{4} 0.25 * n I_{S i(n A l)}}
$$

In this equation, $n$ represents the number of aluminum atoms connected to silicon through an oxygen bridge, and a value of 4.34 for the Si:Al ratio pertains to justify a mostly clinoptilolite designation.

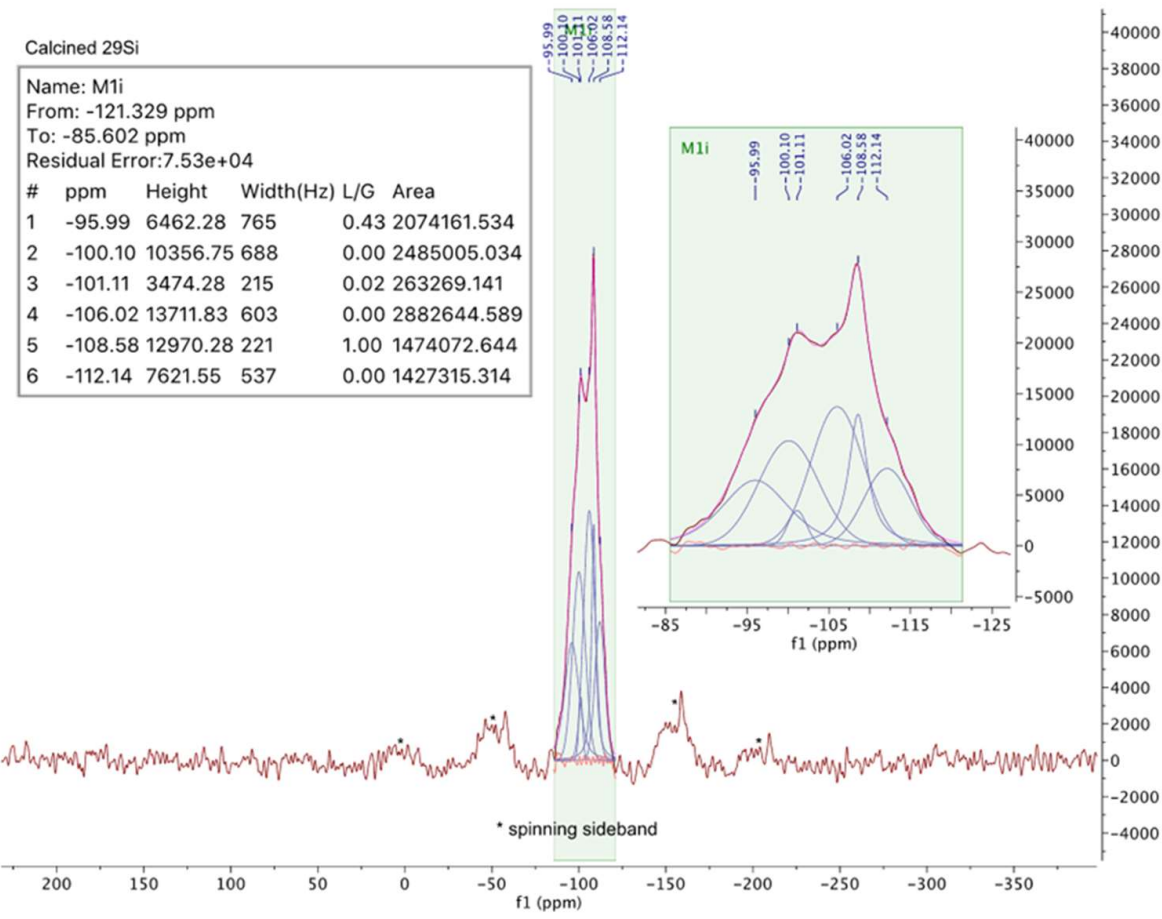

Figure 11. The ${ }^{29} \mathrm{Si}$ NMR spectrum of calcined NV-Na referenced externally to a sample of talc at $98.1 \mathrm{ppm}$ relative to tetramethylsilane (TMS) at $0 \mathrm{ppm}$. The shaded inset depicts the obtained resonances on top and the deconvoluted components of the fit below. 
There are dramatic changes to the ${ }^{29} \mathrm{Si}$ NMR spectrum of the $30 \mathrm{~min} \mathrm{HCl} \mathrm{NV}-\mathrm{Na}$, Fig. 12, compared to NV-Na, Fig. 11. A peak (ppm) and area percentage profile of -91.13 $(1.83 \%),-94.01(1.97 \%),-97.51(9.25 \%),-102.81(22.40 \%),-108.37(39.36 \%)$ and -112.33 $(25.19 \%)$ is obtained. Thus we have the disappearance of the intense clinoptilolite peak at -106.02 present in NV-Na and an increase in the peak at -108.37 which was ascribed above to $\left(\mathrm{SiO}_{2}\right)_{n}$ entities. The peaks at -91.13 and -94.01 may be due to $\mathrm{SiOH}$ and $\mathrm{Si}(\mathrm{OH})_{2}$ groups and the peaks at -97.51 and -102.81 ppm correspond to silicon being connected to either 1 or 2 aluminum atoms via oxygen atom bridges [43]. As the nature of this modified zeolite is not known precisely, the Si:Al ratio cannot be assessed.

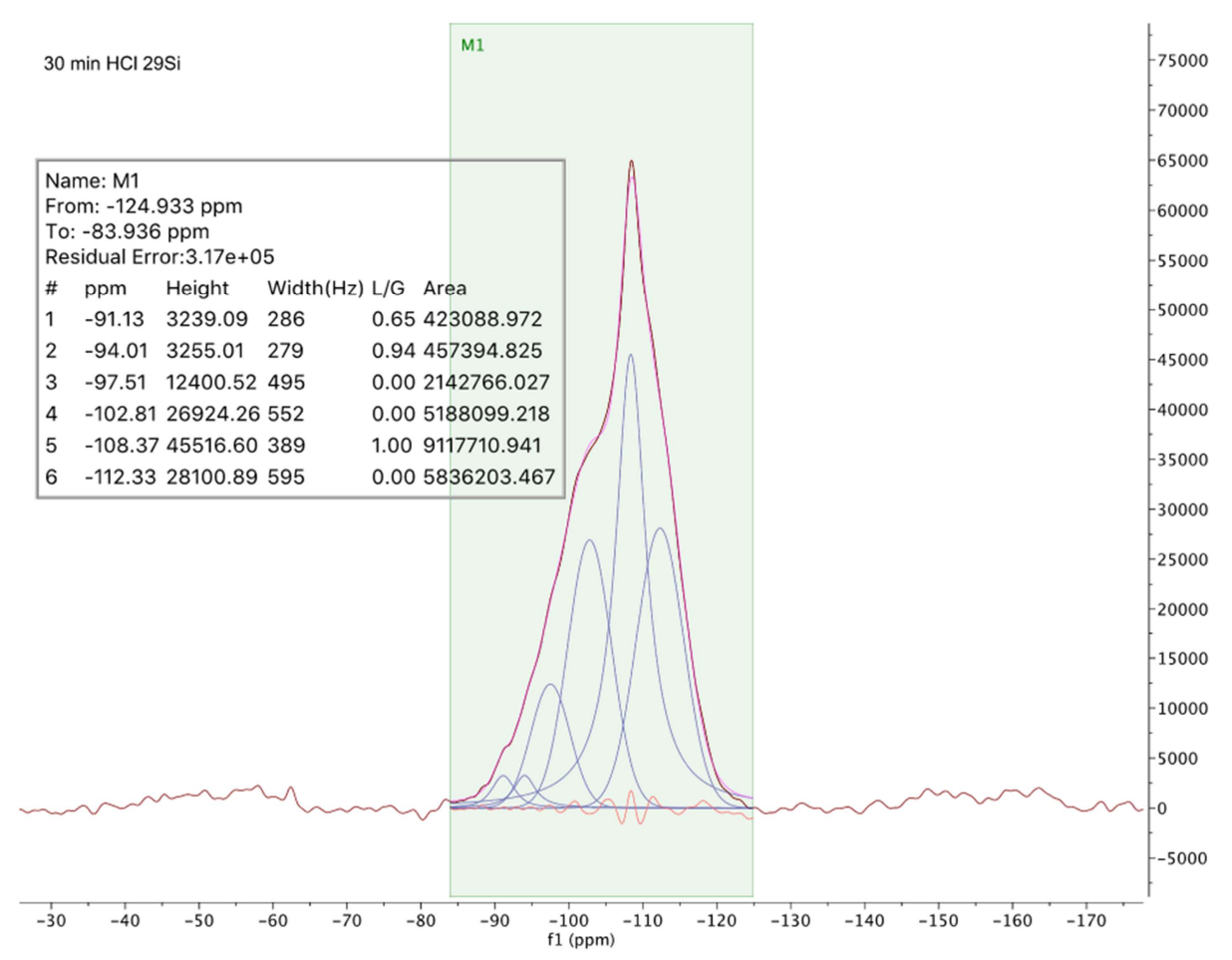

Figure 12. The ${ }^{29} \mathrm{Si} \mathrm{NMR}$ spectrum of $30 \mathrm{~min} \mathrm{HCl} \mathrm{NV-Na}$ referenced externally to a sample of talc at $-98.1 \mathrm{ppm}$ relative to TMS at $0 \mathrm{ppm}$. The resonances on top are from the sample and the deconvoluted components of the fit are below.

\subsection{SEM}

Scanning electron micrographs of calcined NV-Na and 30 min HCl NV-Na were obtained as presented in Fig. 13. The overall morphology of calcined NV-Na looks smoother than those published at an equal magnification (i.e., $10 \mu \mathrm{m}$ ) and somewhat larger, approx. $20 \mu \mathrm{m}$ compared to $5 \mu \mathrm{m}$ [46]. $\mathrm{HCl}$ treatment results in a much less "smooth" surface comparing the images in Fig. 13 (b) for calcined NV-Na and (e) for 30 min HCL NV-Na and there appear to be many more voids which correlates positively with the increase in surface area measurements from the BET calculations. The $5 \mu \mathrm{m}$ images for the samples consist of smooth surfaces albeit with smaller particle sizes for the 30 min $\mathrm{HCl} \mathrm{NV-Na.}$ 

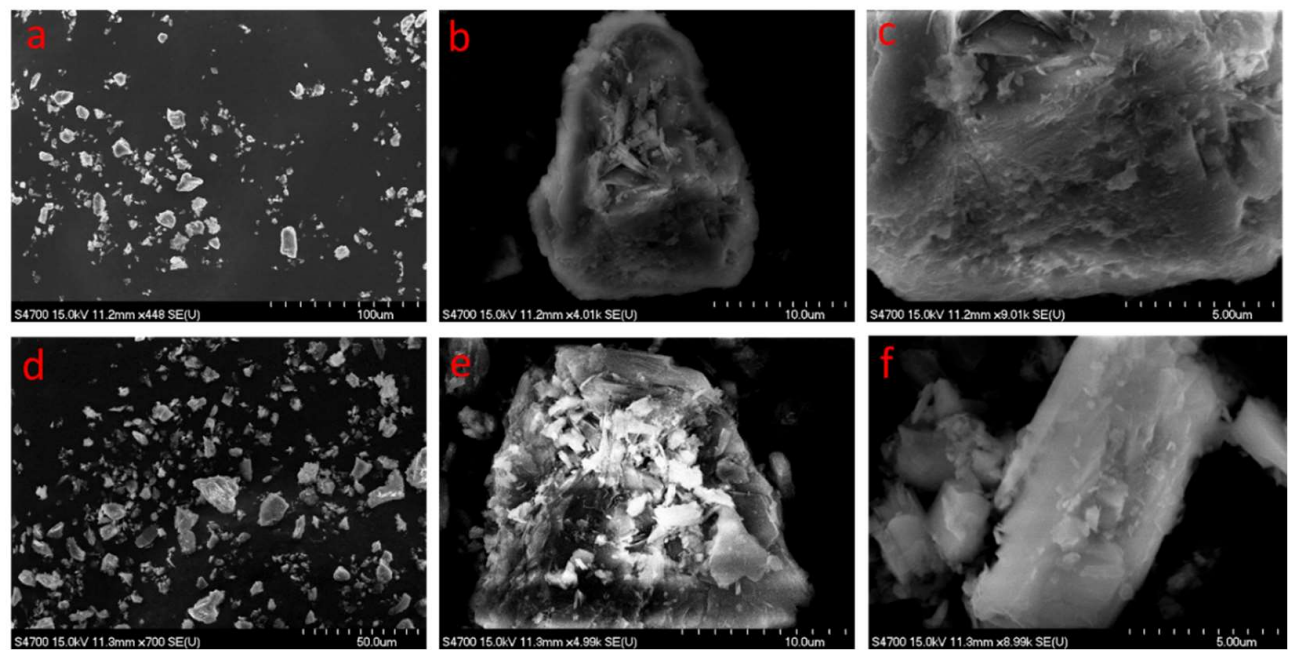

Figure 13. The SEM images of calcined NV-Na at a $100 \mu \mathrm{m}$ scale (a), a $10 \mu \mathrm{m}$ scale (b), and a $5 \mu \mathrm{m}$ scale (c) and that of $30 \mathrm{~min} \mathrm{HCl} \mathrm{NV-Na}$ at a $50 \mu \mathrm{m}$ scale (d), a $10 \mu \mathrm{m}$ scale, (e), and a $5 \mu \mathrm{m}$ scale (f).

\subsection{FTIR}

The FTIR spectra for the calcined and $\mathrm{HCl}$-modified clinoptilolites are displayed in Fig. 14. All contain a small absorption around $1650 \mathrm{~cm}^{-1}$ which has been ascribed to a deformation vibration of residual water bound up inside of the zeolite [47]. The very large broad absorption is due to stretches of the Si-O or Al-O bonds of a tetrahedral nature in the zeolite. It is noteworthy that the center of this absorption shifts from 1024 to $1071 \mathrm{~cm}^{-1}$ for the calcined NV-Na to 30 min $\mathrm{HCl} \mathrm{NV-Na.} \mathrm{Quartz} \mathrm{is} \mathrm{known} \mathrm{to} \mathrm{have} \mathrm{a} \mathrm{large} \mathrm{absorption}$ around $1088 \mathrm{~cm}^{-1}$ [48] and the fact that this peak for the $30 \mathrm{~min} \mathrm{HCl} \mathrm{NV-Na}$ occurs at 1071 $\mathrm{cm}^{-1}$ would suggest that most of the non-Si elements were removed in the $\mathrm{HCl}$ treatment, leaving behind essentially porous quartz. The peaks around $795 \mathrm{~cm}^{-1}$ are due to the symmetric stretch of $\mathrm{Si}-\mathrm{O}$ or Al-O bonds of a tetrahedral nature of the zeolite [49]. Finally, the peak that appears in calcined NV-Na at $672 \mathrm{~cm}^{-1}$ is indicative of an octahedral species most likely aluminum or iron [47]. 


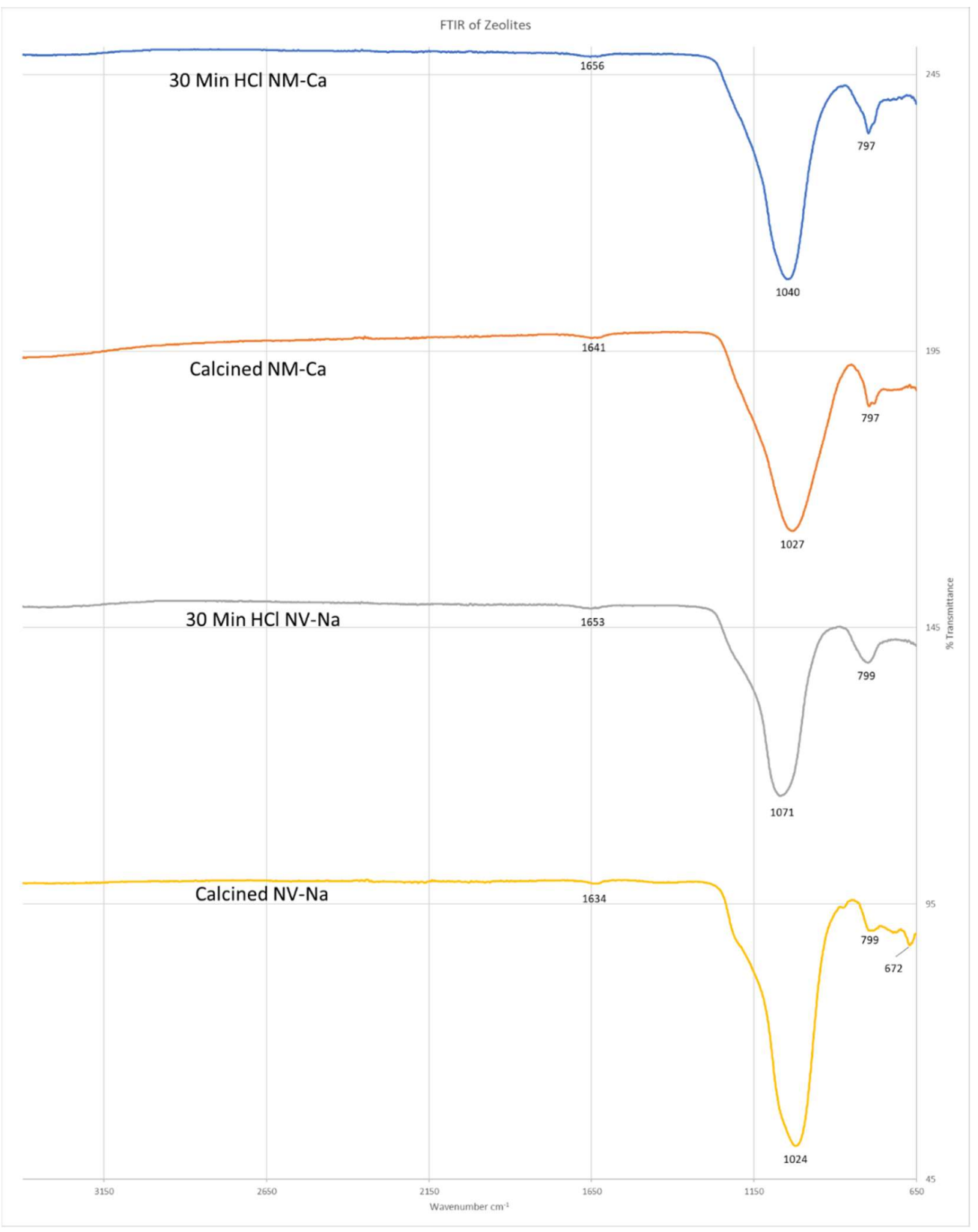

Figure 14. The FTIR spectra of Calcined NV-Na, 30 min HCl NV-Na, Calcined NM-Ca, and 30 min $\mathrm{HCl} \mathrm{NM-Ca.}$

\section{Conclusions}

Of the four zeolites studied AZLB-Ca, AZLB-Na, NV-Na, and NM-Ca, the two chabazites (AZLB-Na and AZLB-Ca) lost structural integrity after boiling in concentrated $\mathrm{HCl}$ acid. These materials lost all crystallinity as is evident by the amorphous pattern generated in the powder X-ray diffraction patterns. Zeolites NV-Na and NM-Ca, which are clinoptilolites, withstood boiling in concentrated $\mathrm{HCl}$ acid as can be seen by the remaining sharp peaks in their powder X-ray diffraction spectra. Results from X-ray fluorescence measurements confirmed that concentrated $\mathrm{HCl}$ acid was effective at removing aluminum, calcium, magnesium, sodium, potassium, and iron from the framework. These two results suggested that NM-Ca had a higher concentration of quartz impurities than NV$\mathrm{Na}$. The increase in pore size/ or increase in the number of pores by removing atoms from the structure was confirmed via BET surface area analysis. A lead removal study 
performed to determine whether the increase in pore size/ or increase in the number of pores after the acid treatment would result in increased capturing of lead ions, found that the acid treatment decreased the ability of the zeolite to absorb lead ions from the solution. This increase in surface area of the natural zeolites due to the acid treatment was not useful at increasing the cation removal or ion exchange capabilities.

Author Contributions: Conceptualization, R.L.; methodology, R.L., N.N.; formal analysis, N.N., R.L.; investigation, G.H., N.N.; resources, R.L., M.M.; data curation, G.H., N.N.; writing-original draft preparation, N.N., R.L.; writing - review and editing, R.L., N.N, G.H., M.M.; visualization, N.N., R.L.; supervision, R.L.; project administration, R.L., N. N.. All authors have read and agreed to the published version of the manuscript."

Funding: This research received no external funding.

Acknowledgments: Special thanks to Jared Edwards for obtaining and Professor Tarun Dam for paying for the SEM images, Edward Laitila for assistance with the XRF measurements, and Director Daniel Holmes of the Max T. Rogers NMR Facility at Michigan State University for the solid-state NMR spectra. The zeolites were generously donated by the St. Cloud Mining Company. We thank Michigan Technological University for its support.

Conflicts of Interest: The authors declare no conflict of interest.

\section{References}

1. Virta, R.L., Zeolites. U.S. Geological Survey Minerals Yearbook 2001, 1-5.

2. Smith, J.V., Origin and structure of zeolites. ACS Monogr. 1976, 171, 3-79.

3. Mumpton, F.A., La roca magica: Uses of natural zeolites in agriculture and industry. Proceedings of the National Academy of Sciences 1999, 96, 3463.

4. Wen, J.; Dong, H.; Zeng, G., Application of zeolite in removing salinity/sodicity from wastewater: A review of mechanisms, challenges and opportunities. J. Cleaner Prod. 2018, 197, 1435-1446.

5. Krstic, V.; Urosevic, T.; Pesovski, B., A review on adsorbents for treatment of water and wastewaters containing copper ions. Chem. Eng. Sci. 2018, 192, 273-287.

6. Chojnacka, M.; Sobolewska, P.; Petrus, R.; Warchol, J., Cr(vi) sorption on surface-modified natural zeolites. Przem. Chem. 2017, 96, 332-337.

7. Ates, A.; Akgül, G., Modification of natural zeolite with naoh for removal of manganese in drinking water. Powder Technol. 2016, 287, 285-291.

8. Zhao, Y., Review of the natural, modified, and synthetic zeolites for heavy metals removal from wastewater. Environ. Eng. Sci. 2016, 33, 443-454.

9. Wang, K., Method and regeneration of sodium modified zeolites for treatment of ammonia-nitrogen wastewater. Shuichuli Jishu 2016, 42, 118-120.

10. Shi, H.; Wei, L.; Yan, C.; Li, X., Research progress of phosphorus removal by zeolite in wastewater. Guangdong Huagong 2014, 41, 165, 169.

11. Regmi, U.; Boyer, T.H., Ammonium and potassium removal from undiluted and diluted hydrolyzed urine using natural zeolites. Chemosphere 2021, 268, 128849.

12. Zwain, H.M.; Vakili, M.; Dahlan, I., Waste material adsorbents for zinc removal from wastewater: A comprehensive review. Int. J. Chem. Eng. 2014, 347912/347911-347912/347913, 347914 pp.

13. Suhartana; Sukmasari, E.; Azmiyawati, C., Modification of natural zeolite with fe(iii) and its application as adsorbent chloride and carbonate ions. IOP Conference Series: Materials Science and Engineering 2018, 349, 012075.

14. Armbruster, T.; Gunter, M.E., Crystal structures of natural zeolites. Reviews in Mineralogy and Geochemistry $2001,45,1-67$.

15. Ambrozova, P.; Kynicky, J.; Urubek, T.; Nguyen, V.D., Synthesis and modification of clinoptilolite. Molecules 2017, $22,1107$. 
16. Ruíz-Baltazar, A.; Esparza, R.; Gonzalez, M.; Rosas, G.; Pérez, R., Preparation and characterization of natural zeolite modified with iron nanoparticles. Journal of Nanomaterials 2015, 2015, 364763.

17. Wani, A.L.; Ara, A.; Usmani, J.A., Lead toxicity: A review. Interdisciplinary toxicology 2015, 8, 55-64.

18. Coombs, D.S.; Alberti, A.; Armbruster, T.; Artioli, G.; Colella, C.; Galli, E.; Grice, J.D.; Liebau, F.; Mandarino, J.A.; Minato, H., et al., Recommended nomenclature for zeolite minerals: Report of the subcommittee on zeolites of the international mineralogical association, commission on new minerals and mineral names. Can. Mineral. 1997, 35, 1571-1606.

19. Thrush, K.A.; Kuznicki, S.M., Characterization of chabazite and chabazite like zeolites of unusual composition. J. Chem. Soc. Faraday Trans. 1991, 87, 1031-1035.

20. Kuznicki, S.M.; Lin, C.C.H.; Bian, J.; Anson, A., Chemical upgrading of sedimentary na-chabazite from bowie, arizona. Clays Clay Miner. 2007, 55, 235-238.

21. Yazdanbakhsh, F.; Alizadehgiashi, M.; Sawada, J.A.; Kuznicki, S.M., A clinoptilolite-pdms mixed-matrix membrane for high temperature water softening. Water Sci Technol 2016, 73, 1409-1417.

22. An, W.; Zhou, X.; Liu, X.; Chai, P.W.; Kuznicki, T.; Kuznicki, S.M., Natural zeolite clinoptilolite-phosphate composite membranes for water desalination by pervaporation. Journal of Membrane Science 2014, 470, 431-438.

23. Adamaref, S.; An, W.; Jarligo, M.O.; Kuznicki, T.; Kuznicki, S.M., Natural clinoptilolite composite membranes on tubular stainless steel supports for water softening. Water Sci Technol 2014, 70, 1412-1418.

24. Kesraoui-Ouki, S.; Cheeseman, C.; Perry, R., Effects of conditioning and treatment of chabazite and clinoptilolite prior to lead and cadmium removal. Environmental Science \& Technology 1993, 27, 1108-1116.

25. Jang, H.K.; Chung, Y.-D.; Whangbo, S.W.; Lyo, I.W.; Whang, C.N.; Lee, S.J.; Lee, S., Effects of chemical etching with hydrochloric acid on a glass surface. Journal of Vacuum Science \& Technology A: Vacuum, Surfaces, and Films 2000, 18, 25632567.

26. Garcia-Basabe, Y.; Rodriguez-Iznaga, I.; de Menorval, L.-C.; Llewellyn, P.; Maurin, G.; Lewis, D.W.; Binions, R.; Autie, M.; Ruiz-Salvador, A.R., Step-wise dealumination of natural clinoptilolite: Structural and physicochemical characterization. Microporous Mesoporous Mater. 2010, 135, 187-196.

27. Altomare, A.; Corriero, N.; Cuocci, C.; Falcicchio, A.; Moliterni, A.; Rizzi, R., Qualx2.0: A qualitative phase analysis software using the freely available database pow_cod. J. Appl. Cryst. 2015, 48, 598-603.

28. O'Neill, L., Icdd annual spring meetings. Powder Diffr. 2013, 28, 137-148.

29. Abuyaghi, A.; El-Bishtawi, R., Removal of lead and nickel ions using zeolite tuff. J. Chem. Technol. Biotechnol. 1997, 69, 27-34.

30. Collection of simulated xrd powder patterns for zeolites. Elsevier: Amsterdam - London - New York - Oxford - Paris - Shannon Tokyo, 2001; p 586.

31. Keller, E.B.; Meier, W.M.; Kirchner, R.M., Synthesis, structures of alpo4-c and alpo4-d, and their topotactic transformation. Solid State Ionics 1990, 43, 93-102.

32. Galli, E.; Gottardi, G.; Mayer, H.; Preisinger, A.; Passaglia, E., The structure of potassium-exchanged heulandite at 293,373 and 593 k. Acta Crystallogr. Sect. B: Struct. Sci. 1983, 39, 189-197.

33. Koyama, K.; Takeuchi, Y., Clinoptilolite: The distribution of potassium atoms and its role in thermal stability. Zeitschrift für Kristallographie-Crystalline Materials 1977, 145, 216-239.

34. Levien, L.; Prewitt, C.T.; Weidner, D.J., Structure and elastic properties of quartz at pressure. Am. Mineral. 1980, 65, 920-930.

35. Arletti, R.; Quartieri, S.; Vezzalini, G., Elastic behavior of zeolite boggsite in silicon oil and aqueous medium: A case of highpressure-induced over-hydration. Am. Mineral. 2010, 95, 1247-1256.

36. St. Cloud mining company. https://www.stcloudmining.com/sales/data-sheets-applications/ accessed 6/4/2021.

37. Oter, O.; Akcay, H., Use of natural clinoptilolite to improve water quality: Sorption and selectivity studies of lead(ii), copper(ii), zinc(ii), and nickel(ii). Water Environ. Res 2007, 79, 329-335. 
38. Inglezakis, V.J.; Loizidou, M.D.; Grigoropoulou, H.P., Equilibrium and kinetic ion exchange studies of pb2+, cr3+, fe3+ and cu2+ on natural clinoptilolite. Water Res. 2002, 36, 2784-2792.

39. Shannon, R., Revised effective ionic radii and systematic studies of interatomic distances in halides and chalcogenides. Acta Crystallographica Section A 1976, 32, 751-767.

40. Santiago, O.; Walsh, K.; Kele, B.; Gardner, E.; Chapman, J., Novel pre-treatment of zeolite materials for the removal of sodium ions: Potential materials for coal seam gas co-produced wastewater. SpringerPlus 2016, 5, 571-571.

41. Lippmaa, E.; Samoson, A.; Magi, M., High-resolution aluminum-27 nmr of aluminosilicates. J. Am. Chem. Soc. 1986, 108, 1730-1735.

42. Holzinger, J.; Nielsen, M.; Beato, P.; Brogaard, R.Y.; Buono, C.; Dyballa, M.; Falsig, H.; Skibsted, J.; Svelle, S., Identification of distinct framework aluminum sites in zeolite zsm-23: A combined computational and experimental 27al nmr study. The Journal of Physical Chemistry C 2019, 123, 7831-7844.

43. Lippmaa, E.; Maegi, M.; Samoson, A.; Tarmak, M.; Engelhardt, G., Investigation of the structure of zeolites by solid-state high-resolution silicon-29 nmr spectroscopy. J. Am. Chem. Soc. 1981, 103, 4992-4996.

44. Khodabandeh, S.; Davis, M.E., Synthesis of a heulandite-type zeolite by hydrothermal conversion of zeolite p1. Chem. Commun. 1996, 1205-1206.

45. Malfait, W.J.; Halter, W.E.; Verel, R., 29si nmr spectroscopy of silica glass: T1 relaxation and constraints on the si-o-si bond angle distribution. Chem. Geol. 2008, 256, 269-277.

46. Minceva, M.; Fajgar, R.; Markovska, L.; Meshko, V., Comparative study of zn2+, cd2+, and pb2+ removal from water solution using natural clinoptilolitic zeolite and commercial granulated activated carbon. Equilibrium of adsorption. Sep. Sci. Technol. 2008, 43, 1-27.

47. Zendelska, A.; Golomeova, M.; Jakupi, Š.; Lisichkov, K.; Kuvendziev, S.; Marinkovski, M., Characterization and application of clinoptilolite for removal of heavy metal ions from water resources. Geologica Macedonica 2018, 32, 21-32.

48. Shahack-Gross, R.; Bar-Yosef, O.; Weiner, S., Black-coloured bones in hayonim cave, israel: Differentiating between burning and oxide staining. Journal of Archaeological Science 1997, 24, 439-446.

49. Akdeniz, Y.; Ülkü, S., Thermal stability of ag-exchanged clinoptilolite rich mineral. J. Therm. Anal. Calorim. 2008, 94, 703-710. 